\title{
Contemporary Education and Digital Technologies
}

\author{
Mladen Milicevic
}

\begin{abstract}
The introduction of new digital technologies and related media is profoundly redesigning our living and learning. The portion of society that commonly first adapts to the "new" is the young, as they incline to be most open to new experiences. The 19th-Century vision of education that takes place at a single institution, a single classroom, and at a specific time is becoming outdated. Education has to shift to learning that occurs anyplace and anytime, which is what most students are now doing on their own. Today, students acquire knowledge in ways that are self-directed, and involve both peers and adults. Digital media allow students to learn from each other in informal situations, making learning in and out of school "increasingly porous," therefore the educational institutions have a problem, because they compete with learning that takes place in recreational space and is more fluid.
\end{abstract}

Index Terms - Blended learning, social media, smart phones, informal education, obsolete education.

\section{INTRODUCTION}

IBM predicts that in the next couple of years, information will be doubled every 12 hours! Buckminster Fuller created the "Knowledge Doubling Curve"; he noticed that until 1900 human knowledge doubled approximately every century. By the end of World War II knowledge was doubling every 25 years. Today things are not as simple as different types of knowledge have different rates of growth. However, it is evident that a transition from the linear growth of human knowledge to the exponential growth of human knowledge has taken place. It is very important to understand why data, information, and knowledge are actually different things. Unfortunately, these terms are sometimes used interchangeably, which can create major confusion and misunderstandings. Data is always correct because it deals with the "facts of the world." For instance, during the crisis in Ukraine (March 2014) one could see on RT (Russian Television) man talking into the camera and stating that he belongs to the Ukrainian paramilitary group which will kick out the Russian arm forces from Ukraine, should the Ukrainian Army fail to do that on their own. There is no dispute that this footage was aired on RT (data). Now, the RT presented to us that these couple of hundred men armed with nothing but handguns are ready to take on the Russian Army (information). Information captures data at a single point, by the subjective informant. So, the information is not always an accurate reflection of the data. In this case the public is informed by giving certain interpretation of the data (a single man talking into the camera). Computers can store data and information, but cannot store knowledge. Only human brains

Manuscript received April 2, 2014; revised June 17, 2014.

Mladen Milicevic is with the Loyola Marymount University, Los Angeles, USA (e-mail: mmilicev@1mu.edu; tel.: +1-310-989-8867). can store knowledge, but the new signals coming into human brain through our eyes, ears, nose, mouth and skin, constantly update that knowledge. Knowledge is what humans know "biased" by our beliefs and expectations, which are in a constant flux of change as our ideas, memories, predictions, and beliefs, get redefined every day. So, the human brain uses two sources to build this knowledge- information and data. Speaking in semiological terms information and data are the "signs" and knowledge is the human interpretation of those signs. In the case of Ukrainian paramilitary group, different humans will make an infinite number of interpretations regarding the data and information presented to them. I tend to believe that the entire interview was "staged" in order to manipulate the public. But, my knowledge about the world influences my interpretation. Since my knowledge about the world constantly changes, my interpretation of this particular event may change as well. There is certain amount of data in the world, and there is plenty more information than data, however the knowledge in the world in exponentially grater that both data and information.

When comes to education we must be cognizant that the explosion of information is not equivalent to the explosion of knowledge. The major problem of today's education is how to structure information into knowledge. Students are being inundated with undigested information, which can easily create paralysis by having so much that it cannot possibly be digested. One may want to read about Geology, and there are hundreds of thousands of articles to be read. If students don't know where to start and what is the point of reference, they may easily get gridlocked. In that sense, one of the main goals of today's education has to be to teach students, as Socrates stated, not only what they can know, but also what are the limitations of knowing, and what they do not know. Furthermore, our goal in the information age is to seek out and stress the quality of information rather than quantity.

\section{FINDINGS}

It is now untenable to hold onto a notion that in four years a university can turn a freshman student into an educated and refined person. That idea belongs to the past, when in the 16th-Century one could learn everything known at that time about the universe by studying for four years at the university. This outdated vision of education, which happens at a single institution, single place, and at a particular time-is becoming increasingly obsolete. Life has become far more complicated since the inception of the old all-inclusive, academic strategy. Today is nearly impossible in four educational years to give a student all the possible elements of professionalism, know-how, career, and also a vocation. All the university can provide is an introduction to learning, to allow us to discover our possibilities, and our potentials. 
The current educational system was shaped during the Industrial Revolution, and it was created to efficiently convey information from the instructor to the students in the traditional classroom setting. This system was based on linearity, conformity and standardization. Now, since the Information Age took over from the Industrial Age, the educational models are being forced to follow that changeover. Unfortunately, the role and the form of higher education have hardly changed; aside from PowerPoint presentations replacing most writing-on-a-blackboard styled ones. In the digital age the learning environment is completely blown open. The advent of new digital technology and social media is fundamentally reshaping our living and learning. The segment of society that usually first adapts to the "new" is the young, as they tend to be most open to new experiences. We see youth becoming much more involved in exchanging information and knowledge over the web than ever before. Consequently, we are finding that students are learning much more in these informal environments because they are voluntarily engaging in information, which they find interesting.

The dominant forces in children's lives are the media; either traditional television or the "new media" (including cell phones, iPads, and social media). The average 8- to 10 -year-old devotes approximately 8 hours a day to a variety of different media contents, while older children and teenagers devote $>11$ hours per day. [1] Adolescents now spend more time with media than they do in school-it is the principal activity for children and teenagers other than sleeping. [1], [2] TV still remains the predominant medium of choice ( $>4$ hours per day) but almost $1 / 3$ of the TV programming gets viewed on non-TV platforms such as computers, iPads, or cell phones. Practically all youngsters have access to the Internet (84\%), usually high-speed, and $1 / 3$ have access in their own bedroom. The time spent on a computer amounts to 1.5 hours per day; out of which half is spent in social networking, playing games, or viewing videos. New digital technology has made a huge impact on the life of youngsters: $75 \%$ of 12 - to 17 -year-olds now own cell phones, up from $45 \%$ in 2004 . Nearly all teenagers $(88 \%)$ use text messaging. They actually talk less on their phones than any other age group except for senior citizens. [3], [4] Half of teenagers send 50 or more text messages per day, and one-third send more than 100 per day. [3] Teenagers mostly access social media sites from cell phones. [4] They are also avid multitaskers, often using several technologies simultaneously [1].

With this constantly changing landscape education should become less institutionalized and more personalized. Digital technologies and social media allow students to learn from each other in informal settings anywhere and anytime, making learning in and out of school "increasingly porous." Therefore the institutions have a problem, because they compete with learning that takes place in recreational space and is more fluid. Today students learn in ways that are self-directed, and involve both peers and adults. When you go online, social networking sites, a video game, etc., you can be interacting with thousands of people (many of whom are your peers). Peers play hugely important roles in the learning environments of the 21 st-Century. This kind of learning is handled intuitively, with inherent enthusiasm, and with the interplay between peers learning and working intuitively toward shared objectives. It is quite understandable how the current educational system is inadequate to guide and evaluate such "uncommon" learning, which seems more effective and valuable in many contexts than rote memorization.

However, we must be cognizant that today's children and young adults spend an enormous amount of time ingesting all kinds of information useless and erroneous information. That is the nature of the Internet where Wikipedia and Encyclopedia Britannica stand next to each other as if they were equal. Superficial content gets far more attention than something that has serious depth. Watching silly videos on YouTube is equally accessible as watching the educational videos on science, and it is not hard to guess which ones get more hits. So, these are the kinds of minds that will be enrolling into the universities, which are predominantly populated by the educators who got educated when the Internet and cyberspace did not exist.

It is easy to expect people to be more creative but the prevailing paradigm in education, politics, and business is conformity. Everybody wants the creativity and innovation but not the risk of failing. But creativity needs the freedom to explore, investigate, and fail in search of breaking new grounds. Tensions between traditional models of education and the new uses of digital technologies and media widely exist, in spite of the urgencies of these technologies and their inevitable reshaping the old system of education. The unwillingness of administrators to adapt is estimated to be the main obstacle to incorporating more digital and social media tools into classrooms. Advocates of social media in the classroom claim that social media tools can ignite students' curiosity and ingenuity, exposed them to content experts and real-world examples of classroom lessons, help them become civically engaged, and allow them to collaborate with peers worldwide, while empowering them to direct their own learning. Digital and social media tools can also support students to develop technological skills; to be creative; and to critique, analyze, and evaluate multimedia text, as well as manage, analyze, and synthesize multiple streams of information.

All this is happening in a society that is changing at far too fast a rate to rely on past information as a means of educating people. One of the most convincing factors is the diminishing half-life of knowledge. The "half-life of knowledge" is the time period measured from when knowledge is gained to when it becomes obsolete. Half of what is known today was not known 10 years ago. The amount of knowledge in the world has doubled in the past 10 years and is doubling every 18 months according to the American Society of Training and Documentation (ASTD). To combat the shrinking half-life of knowledge, educational institutions must develop new methods of instruction. But, traditional systems of learning and governing are antiquated, and far too linked to a limited notion of intelligence. Today's teaching has two fundamental challenges. It has to provide a base of knowledge; but, more importantly, it has to provide connections between the subjects and between the disciplines. In traditional educational settings we thought about learning 
environments as the interaction between a teacher, a student, and curriculum (the content which a student supposed to be learning). New digital technology and media also allow specifically and personally tailored instruction to a great numbers of students. The result is a new form of culture where knowledge is seen as fluid and evolving, the personal is both enriched and fine tuned in relation to the collective, and the ability to participate and interconnect in the world is governed by the play of the imagination. This type of education appears more like home schooling or apprenticeship, in which students decide the terms and conditions of their learning rather than following a prescribed route. This will encourage a higher level of specialization, and "just-in-case" learning would not be of much significance any more. Since students would be aiming toward their personal interests, they would be far more motivated to learn. Though the new technology creates far-reaching opportunities it also brings substantial challenges. For example, the universities provide a common physical space for a diverse group of students to interact in the real world while being educated about prejudice, tolerance, and social justice. This would be hard to attain though online type of instruction alone.

According to a 2012 U.S. Department of Education study, students who took all or part of their instruction online performed better, on average, than those taking the same course through face-to-face instruction. In addition, those who took "blended" courses — those that combine elements of online learning and face-to-face instruction - seemed to do best of all. Many universities report that blended instruction represents the fastest-growing type of enrollment. A blended learning approach means that face-to-face instruction turns out to be more effective because the mundane elements of basic instruction are moved to an e-learning environment, which can be more engaging and interactive. When students do meet in the classroom with an instructor, the face-to-face class can now focus on higher-level skills since the basics are known by all students and were already covered through the e-learning part of the class.

The most recent study of from January 2014 surveyed roughly 350 US University Presidents and found out that more than $90 \%$ of them strongly believe that hybrid (blended) classes are highly effective. To the contrary, they were largely hostile toward MOOCs, even though almost none have had any experience in teaching or taking a MOOC.[5] However, only one third of them believe that the US higher education is heading in right direction, while two thirds think that the pace of change needed for the universities to catch up with the rapid changes in society is too slow. But ideas for change in the US higher education may be found everywhere. There are numerous conferences discussing topics ranging from MOOCs to competency-based degrees. Many believe that the focus should be on changing the models of teaching and learning. However, on top of everything comes the politics related to these issues.

All these point out the urgent need to develop coherent models for the future of education in a rapidly changing technological age. There will be much to gain, and perhaps some losses as well. We have this ideal of how one teacher may profoundly affect a great number of students. Many of us could think of such a teacher. We may hardly remember what the core curriculum was and what the courses were but we remember the one teacher who affected us the most. But that ideal vision may be rapidly disappearing in this new educational environment, that style of teaching may be a matter of the past.

\section{CONCLUSION}

The world is changing. Employment opportunities are changing. Education needs to facilitate teaching knowledge, but there is a general consensus emerging in that we need a better way to prepare young minds for an uncertain future. Universities have been notorious for being slow in adopting changes, but the society and the profile of students who are enrolling into the universities is changing at a speed that is becoming increasingly difficult to handle. Accommodating this new generation of ever-changing students is going to be a monumental task for institutions of higher education. Traditional models of teaching and education, which were established long time ago are now becoming increasingly obsolete, ineffective, and unattractive for the new generation of students. These educational approaches must change as universities rethink their traditional roles and their modes of operation. Embarking onto completely new roles and missions, driven by global social, technological and economic changes, is going to be a rather painful process.

Usually, when we think of culture, we think of a current, established entity that slowly transforms and evolves over long periods of time. But there is another sense of culture, one that reacts to its environment organically. It not only adapts to the environmental changes, but it integrates the very notion of change into its processes as one of its environmental variables. Only this kind of culture can be flexible enough to survive the exponential rate of change which the information age has brought upon us. Thus, by exploring play, creativity, and the refinement of inventiveness as foundations of education, we may embark onto the future of learning that is attainable, scalable and one that flourishes along with the technology.

\section{REFERENCES}

[1] V. Rideout, "Generation M2: Media in the Lives of 8- to 18-Year-Olds," Menlo Park, CA: Kaiser Family Foundation, 2010

[2] V. C. Strasburger, A. B. Jordan, and E. Donnerstein, "Health effects of media on children and adolescents," Pediatrics, vol. 125, no. 4, pp. 756-767, 2010

[3] A. Lenhart. (January 2014). Teens, Smartphones and Texting. Washington, DC: Pew Internet and American Life Project. [Online]. Available:

http://www.pewinternet.org/ /media/Files/Reports/2012/PIP_Teens_S martphones_and_Texting.pdf

[4] A. Lenhart, R. Ling, S. Campbell, and K. Purcell. (January 2014). Teens and Mobile Phones. Washington, DC: Pew Internet and American Life Project. [Online]. Available :http://www.pewinternet.org/ /media//Files/Reports/2010/P IP-Teens-and-Mobile-2010-with-topline.pdf

[5] Survey conducted by Maguire Associates, Chronicle of Higher Education. The Innovative University: What College Presidents Think about Change in American Higher Education [Online]. Available: http://strategicplanning.fairfield.edu/sites/default/files/innovative_uni versity_140516.pdf 


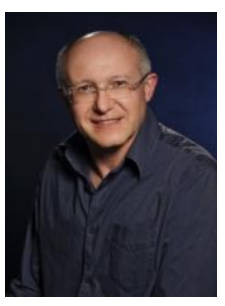

Mladen Milicevic received a B.A. 1982 and an M.A 1986 in music composition and multimedia arts studying with Josip Magdic at The Music Academy of Sarajevo, in his native Bosnia-Herzegovina. In 1986 Mr. Milicevic came to the United States to study with Alvin Lucier at Wesleyan University in Connecticut, from which he received his masters in experimental music composition 1988. From the University of Miami in Florida, Mr. Milicevic received his doctorate in computer music composition in 1991, studying with Dennis Kam. For several summers he studied with Michael Czajkowski at the Aspen Music School. He was awarded several music prizes for his compositions in the former Yugoslavia as well as in Europe. Working in Yugoslavia as a freelance composer for ten years, he composed for theater, films, radio and television, also receiving several prizes for this body of work. Since he moved to the United States in 1986, Mr. Milicevic has performed live electronic music, composed for modern dances, made several experimental animated films and videos, set up installations and video sculptures, had exhibitions of his paintings, and scored for films. His interests are interdisciplinary and he has made numerous presentations at various international conferences on a wide range of topics such as music, film, aesthetics, semiology, neuroscience, sociology, education, artificial intelligence, religion, and cultural studies.

In his academic carrier Mladen Milicevic has served on numerous committees such as rank and tenure, core curriculum, academic technology, university website, mission and identity, faculty senate with many sub-committees, various faculty and administrative search committees, etc Mr. Milicevic is professor and chair of Recording Arts Department at Loyola Marymount University, Los Angeles. 